Research note

\title{
The Difference Between Self-reported and Perceived Survey Measures and the Implications for Political Socialization Research
}

\author{
Political Science Research and Methods (Accepted, December 2015)
}

\author{
Joris Boonen, Ellen Quintelier \& Marc Hooghe \\ Centre for Citizenship and Democracy, University of Leuven
}

\begin{abstract}
Within research on the political influence that social network members exert on one another, some studies rely on information obtained directly from different members in the network separately (selfreported measures), while others rely on information obtained from one key informant within the social network (measures based on perception). In this research note, we investigate the difference between these self-reported and perceived measures by analyzing the correspondence of voting intentions within the family. On the one hand, we examine this correspondence using information obtained from only one family member. On the other hand, we use the self-reported measures obtained from all family members separately. To analyze the differences and the implications of both approaches, we use data from the Parent-Child Socialization Study (PCSS), a survey conducted among 2,085 mothers, fathers and children in the Flemish region of Belgium (2012). Our analyses suggest that using perceptual measures can be problematic in many ways and could lead researchers to different or even opposite conclusions than using self-reported measures from all individual respondents.
\end{abstract}

Keywords: Perceptual accuracy; vote choice; intergenerational transmission; survey research; political socialization; Parent-Child Socialization Study (PCSS) 


\section{MAIN TEXT}

Within political socialization research and social network studies, researchers have made use of both individual questionnaires and from information gained from key informants. In the first case every social network member reports directly, in the latter one member reports on what s/he perceives to be the preferences of others. However, there is hardly any research on the differences between the results obtained from both methods. One of the studies that has been conducted in this respect was conducted by Acock and Bengtson (1980), who explored the difference between actual and perceived similarity between parents and children. They used a limited dataset of 466 mother-father-child triads to investigate whether stated attitudes (what parents think) or attributed attitudes (what children report on what their parents think) are the best predictor for adolescents' political orientations. Their results suggest that conclusions drawn from self-administered questionnaires can be completely different from the ones established on the basis of reported information. One of the reasons for the erroneous reports of the adolescent children could be that adolescents project their own attitudes on what they believe are the attitudes of their parents, a mechanism that has been called the 'self-directed bias' (Whitbeck and Gecas 1988; Niemi 1974). This self-directed bias is also documented in the work of Tedin (1976), who argues that adolescents' perceptions should only be used when the actual correlation between parents and children is expected to be very high. In this respect, Westholm (1999) describes a similar pattern in which adolescents are likely to overestimate the impact of the political socialization process and he concludes that 'little confidence should be placed in studies of interpersonal influence based on a single source' (pp. 548). An accurate perception of parental preferences, however, can be enhanced by political discussion within the family, parental value agreement, and political knowledge of the adolescent (Niemi 1974).

In this research note, our aim is to investigate this possible measurement bias more systematically within the setting of political socialization studies. In this particular field, a 
substantial amount of research attention has been devoted to the transmission processes that take place between parents and children (Jennings, Stoker, and Bowers 2009; Zuckerman, Dasović, and Fitzgerald 2007). Some of these studies are based on self-administered questionnaires (e.g. Kroh and Selb 2009), while others are based on reported (thus perceived) information obtained from one family member only (e.g. Nieuwbeerta and Wittebrood 1995). The aim of this research note is to arrive at a better understanding of how the bias in selfreported data can influence our understanding of political socialization processes.

We use data from the Parent-Child Socialization Study (PCSS), conducted among 3,426 15year old adolescents and their parents in the Flemish region of Belgium. Adolescents and both their parents filled out a survey containing questions on their own political preferences. Simultaneously, adolescents were asked how they perceive the political preferences of their parents. This unique dataset allows us to investigate the differences between perceptions of political preferences and self-reported political preferences.

The questions we address are: 1) Can adolescents make a reliable assessment of their parents' voting intentions?; 2) Which factors contribute to an actual or perceived similarity with parental voting intentions?; and 3) What are the implications of the difference between actual and perceived voting intentions for political socialization and social network research?

\section{Data and methods}

The first wave of the PCSS was conducted in 2012 among a representative sample of adolescents and their parents in Belgium (Hooghe et al. 2012). For this study, a sample of 3,426 14-to 15-year old adolescents was interviewed using a written self-administered questionnaire in a stratified random sample of 61 Dutch language schools. All adolescents received a similar questionnaire for both their parents which could be completed at home. In $60.8 \%$ of all cases, 
both parents completed the survey and for $72.7 \%$ of the adolescents at least one parent returned a completed questionnaire.

Looking at gender and educational level, the sample resembles the distribution in the population. Since we will compare mother-child, father-child and mother-father dyads, we can only use complete triads where we have information from both the mother and the father. This brings the total of father-mother-child triads to 2,085 triads with 6,255 individual respondents. In the interpretation of the results, we should take into account that the analyses will not include single-parent households.

The questionnaires included information on the individual preferences of every family member, but also about the perceived preferences of the other family members and this allows for a direct comparison of the effects of actual and perceived attitudes. We use voting intentions as the dependent variable, in line with some of the works on political socialization within the family (Jennings, Stoker, and Bowers 2009; Zuckerman, Dasović, and Fitzgerald 2007). We have opted for the analysis of voting intentions, not only because this can be considered as a summary statement of political positions, but also because this measure leads to clear and discrete choices: either one has the same voting preference as his/her family members, or one does not. Furthermore, voting intention is the only variable in the PCSS survey for which we have both actual individual measures and perceived measures of the parents.

\section{Dependent variable}

\section{Voting intentions}

Voting intention is measured using a standard question: 'If you could vote in an election for the Belgian parliament today, which party would you vote for?'. For both actual and perceived measures, the respondents were given eight options: Christian-Democrats, Greens, Flemish nationalists, Liberals, Socialists, the radical right 'Vlaams Belang', Libertarians and radical left- 
wing socialists, with an additional open response category for 'other party'. A previous analysis showed that adolescents at this age already make a clear decision on voting preferences (Hooghe and Boonen, forthcoming). Adolescents were asked in two separate questions which party they think their mother and their father would vote for, which will be the perceptual measures in this study.

In comparison with other studies, item non-response for these questions remained limited. Non-response rates for the questions on own voting intention are $7.4 \%$ for adolescents, $10.1 \%$ for mothers and $11.9 \%$ for fathers. The non-response rates for the perceived voting intention of the parents are $10.0 \%$ for the perception of the mother and $13.2 \%$ for the perception of the father. The non-response rate was not significantly related to perceived voting intention nor to political knowledge. However, to overcome possible bias, we used multiple imputation for these missing cases (with 20 imputations). We imputed missings for parent-child correspondence, parental homogeneity, correct knowledge and perceived correspondence, using auxiliary variables from both parents' and children's samples (gender, educational level, political interest, voting intention and political discussion within the family). In total, we imputed one or more items for 851 cases (Durrant 2009). In a separate analysis, we also made exactly the same calculations but without imputation, and this did not lead to substantively different results.

\section{Correspondence}

Given the fact that eight different parties for three family members could lead to 512 different combinations, we will not predict every distinct combination, but focus on specific party correspondence between child and parents, one of the main factors that is used to study intergenerational transmission. Since the Belgian parties cannot be ordered on one single ideological dimension or divided in clear party blocs (Deschouwer 2009) we will use a 
conservative estimate of party correspondence that refers to voting for exactly the same party and not include any vague resemblance of party families. Theoretically, voting correspondence within a family triad can have five different outcomes (Figure 1). If all three members of the triad vote for the same party, there is full correspondence (area 1). If all members vote for a different party, there is no correspondence at all (area 2). The three other options are: the child has the same preference as the mother, but a different one than the father (area 3); the child has the same preference as the father, but a different one than the mother (area 4); mother and father have the same preference, but they differ from the child (area 5). Every family can be situated in one of the five areas in Figure 1.

Figure 1. Combinations for Vote Correspondence within Families

Party Mother (PM)

(1) $P M=P F=P C$ : Party Mother=Party Father=Party Child

(2) $\mathrm{PM} \neq \mathrm{PF} \neq \mathrm{PC}$ : No vote correspondence

(3) PM=PC: Party Mother=Party Child

(4) $P F=P C$ : Party Father=Party Child

(5) PM=PF: Party Mother=Party Father

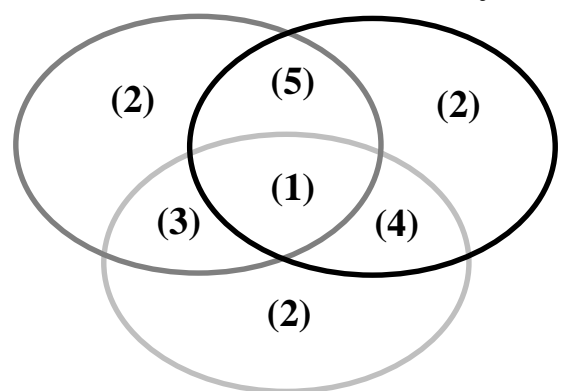

Party Child (PC)

\section{Independent variables}

For the models explaining the correspondence between parents and children, we draw on previous literature to include some of the most important independent variables. These include the homogeneity between parents (Nieuwbeerta and Wittebrood 1995; Jennings and Niemi 1981; Zuckerman, Dasović, and Fitzgerald 2007), political discussion within the family (Kroh and Selb 2009) and the strength of the party preference of the parents (Jennings, Stoker, and Bowers 2009; Niemi 1974). Therefore, we have included parental ideological homogeneity, political discussion with parents and the strength of the parental preferences as main 
independent variables in our regression models. Furthermore, we control for gender, political knowledge and educational level (Jennings, Stoker, and Bowers 2009).

The ideological homogeneity of both parents is taken into account by including the absolute difference between the self-placement of both parents on a 0 to 10 left-right scale. Parental dyads are considered to be homogeneous if this difference is 0 while the maximum difference can take the value of 10 . Next, we include information about the strength of the party preference. Parents were asked to indicate on a 0 to 10 scale how likely it is that they will vote for their preferred party (propensity to vote), which we used as an indication of the strength of their preference. Political discussion with the parents is measured using a 4-point sum scale, asking how often the respondents talk about politics with their mother and their father, with a higher score indicating more discussion. Gender is a dichotomous variable (girl=1). We operationalized Child's education with a dummy variable coded ' 1 ' for the general education track and ' 0 ' for all other educational tracks ${ }^{1}$. As preliminary analyses suggested that vocational, art and technical education are closely related with regard to socioeconomic characteristics, these educational tracks were grouped. For political knowledge, we use a sum scale of four multiple choice political knowledge questions concerning Belgian politics. The total sum scale ranges from 0 (all questions answered wrongly) to 4 (all questions answered correctly). We added the full question wording of all the used variables in the appendix.

\section{Results}

\footnotetext{
${ }^{1}$ The Flemish school system is divided in clearly distinguished educational tracks: general education, technical education, vocational education and a very small track of artistic education. Pupils who are enrolled within the general education track are typically those with the highest level of cognitive skills, who are preparing for higher (university) education (coded 1). For technical, artistic and especially vocational training, further academic training is not considered as a goal, and these tracks are coded as ' 0 ').
} 


\section{Correct knowledge of voting intentions}

First, we explore to what extent the adolescents have a correct perception of the political preferences of their parents. We find that $42.9 \%$ of all adolescents have a correct perception of the voting intention of their father, while $46.5 \%$ has a correct perception of the voting intention of their mother. $30.1 \%$ has a correct perception of the party preference of both their parents. ${ }^{2}$

In a first binomial regression model, we use this correct knowledge on parental voting intentions as a dependent variable (Table 1). We find that respondents with a higher level of political knowledge are more likely to make a correct judgment of the voting intention of both mother and father. Talking about politics with parents also enhances the chances of having a correct knowledge of the voting intention, but this is relation is only significant for the voting intention of the father. We can note that this has nothing to do with talking more frequently about politics with one's father, since we have observed that adolescents talk just as frequently about politics with their mother as with their father. Finally, we can observe that when parents are strongly motivated to vote for a specific party (propensity to vote for selected party) adolescents are more likely to have an accurate perception of this preference. Ideological homogeneity between parents, gender and educational level are not significantly related to the correct assessment of parental voting intentions.

Table 1. Predicting children's correct assessment of parental voting intentions

$\begin{array}{cc}\begin{array}{c}\text { Correct knowledge of } \\ \text { party of father }\end{array} & \text { Correct knowledge of } \\ \text { party of mother }\end{array}$

\footnotetext{
${ }^{2}$ Note that these percentages do only take into account right or wrong answers. The responses for which the outcome was unknown (for instance if the respondent selected 'other' or indicated a 'blanc' vote) are not taken into account in these calculations.
} 


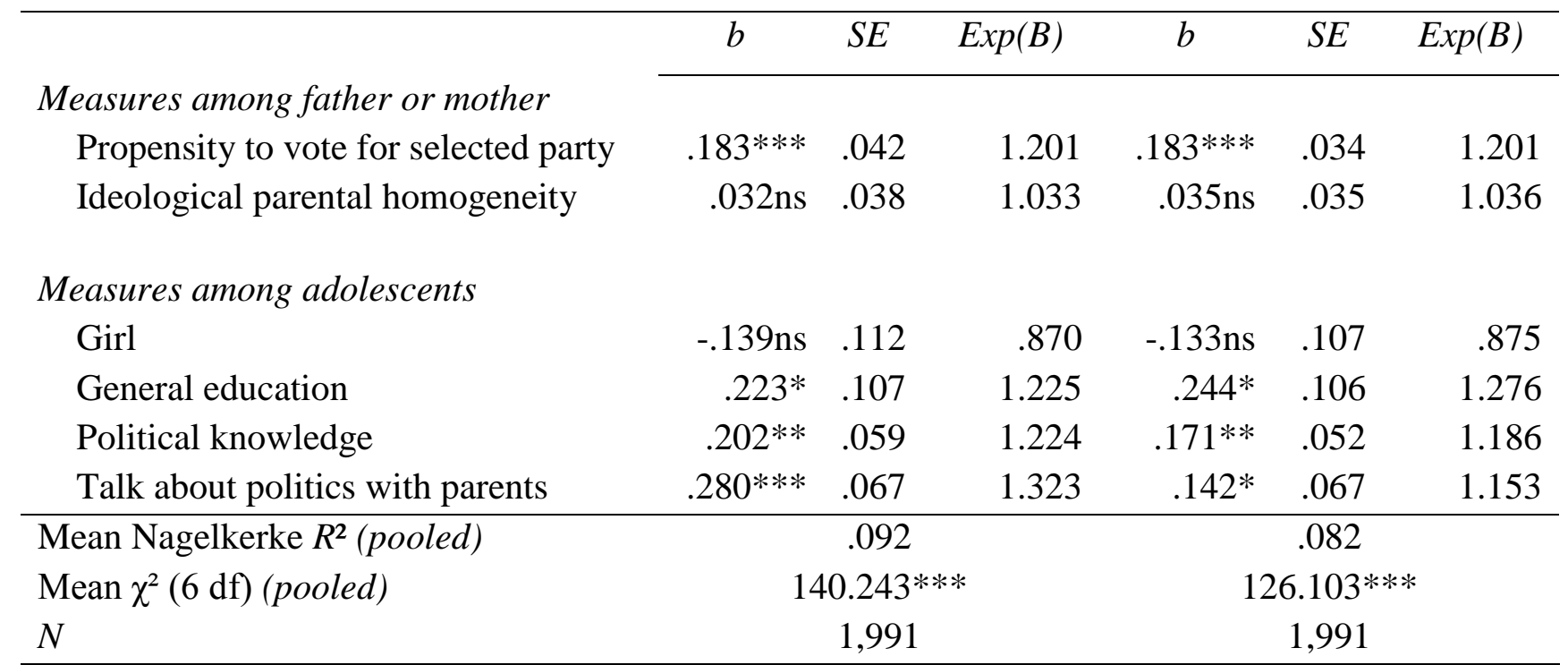

Note: PCSS 2012. Entries are unstandardized b-coefficients from a logistic regression analysis with standard errors $(S E)$ and odds ratios $\operatorname{Exp}(B) . * p<.05 . * * p<.01 . * * * p<.001$. The $\mathrm{N}$ of the analysis is not 2,085 because we have information on cases in the dependent variable that cannot be used (such as 'blanc' or 'invalid' voting intention). We did not code these as missings that should be imputed, but as cases of which the information is not useable in the analyses.

\section{Perceived correspondence between parents and children}

Next, we turn to the main question of this paper: is there a difference between actual intrafamily correspondence and perceived correspondence? In Table 2, we split up the results for the different correspondence measures in three subsamples: one for the entire sample (left column), one for the families in which there is a real correspondence between parent(s) and child (middle column), and one for the families in which there is no correspondence between parent(s) and child (right column). It is clear that there is a strong overestimation of correspondence between family members. In the first column, we can see that more than $60 \%$ of all respondents assume that they have the same vote preference as their father or their mother, while in reality this is no more than $40 \% .53 .3 \%$ of all adolescents think both parents vote for the same party as they do, while this is the case in only $27.7 \%$ of the families. Note that the level of correspondence between mothers and children is higher than the level of correspondence between fathers and children, and this is in line with earlier studies on the intergenerational transmission of party preferences (Jennings and Niemi 1971, 1974; Zuckerman, Dasović, and Fitzgerald 2007). 
In the second column, we can see that adolescents tend to overestimate the degree of resemblance they have with their parents. When there is actual correspondence (with one or both parents) the large majority (e.g. $78.4 \%$ for the mother) of the adolescent respondents are correct in their assessment. Therefore, if there is political correspondence, adolescents seem to be well aware of this and most mistakes are made in the cases where there is no actual correspondence.

The overestimated scores of similarity in the third column of Table 2 are in line with what Niemi (1974, pp. 62) and Tedin (1976) observed in earlier studies and has been called the 'self-directed bias' in adolescent's reports. In the Niemi study, $90 \%$ of the students correctly reported their parent's vote, but when the perception was incorrect, $69 \%$ was in the direction of the student's own preference. Although this study differs strongly in terms of party system, age of the respondents and timeframe in which it took place, the results are in line with the current results, in the sense that there is a strong self-directed bias towards overestimating the correspondence between vote choices. 
Table 2. Actual and perceived correspondence of voting intentions

\begin{tabular}{|c|c|c|c|c|c|c|}
\hline \multirow[b]{3}{*}{$\mathrm{PM}=\mathrm{PC}$} & \multicolumn{2}{|c|}{ Entire sample } & \multicolumn{2}{|c|}{$\begin{array}{l}\text { Subsample with } \\
\text { actual correspondence }\end{array}$} & \multicolumn{2}{|c|}{$\begin{array}{c}\text { Subsample with no } \\
\text { correspondence }\end{array}$} \\
\hline & $\begin{array}{c}\text { Actual } \\
\text { correspondence }\end{array}$ & $\begin{array}{c}\text { Perceived } \\
\text { correspondence }\end{array}$ & $\begin{array}{c}\text { Correctly } \\
\text { predicted } \\
\text { correspondence }\end{array}$ & $\begin{array}{l}\text { Underestimated } \\
\text { correspondence }\end{array}$ & $\begin{array}{c}\text { Correctly } \\
\text { predicted no } \\
\text { correspondence }\end{array}$ & $\begin{array}{l}\text { Overestimated } \\
\text { correspondence }\end{array}$ \\
\hline & 42.9 & 63.0 & 78.4 & 21.6 & 48.5 & 51.5 \\
\hline $\mathrm{PF}=\mathrm{PC}$ & 37.5 & 63.5 & 82.4 & 17.6 & 47.9 & 52.1 \\
\hline $\mathrm{PM}=\mathrm{PF}=\mathrm{PC}$ & 27.7 & 53.3 & 76.5 & 23.5 & 58.4 & 41.6 \\
\hline
\end{tabular}

Note: PCSS 2012. Entries are row percentages. PM=party mother, PF=party father, PC=party child.

\section{Are the two assessments interchangeable?}

While the results in Table 2 have shown that there is some correlation between actual and perceived correspondence, it is important to examine what the determinants are of the difference between both measurements. Therefore, in a next regression model (Table 3) actual and perceived correspondence function as the dependent variable. We limit ourselves to full family correspondence, i.e., families in which all surveyed members vote for the same party. As this a dichotomous variable (full correspondence or not), we use a binomial logistic regression. We construct our model with a number of independent variables that have been found to predict correspondence of political preferences within the family, such as discussing politics within the family, strength of party preference and ideological homogeneity (e.g. Jennings, Stoker, and Bowers 2009; Levine 2005).

First, we can observe that the full model is more effective in predicting actual correspondence (Mean Nagelkerke pseudo- $R^{2}=.089$ ) than correspondence as perceived by the adolescent $\left(R^{2}=.013\right)$. As expected from political socialization theory, the intensity of party preferences among the parents, the homogeneity of parental preferences, political discussion within the family and the level of political knowledge of the adolescent all predict actual correspondence. However, almost none of these coefficients is significant in the corresponding model that is aimed to explain perceived family correspondence (right column). Moreover, we 
even find a negative effect (-.119) of political knowledge on perceived family correspondence, while we found a small positive effect (.110) of political knowledge on actual family correspondence, which can be explained by the fact that less politically knowledgeable adolescents tend to systematically overestimate the correspondence between themselves and their parents. Generally, it is safe to state that the effects run differently for actual and perceived correspondence. Actual correspondence can be explained by political knowledge, parental homogeneity and political discussion within the family, while for perceived correspondence this is not the case. This is an important finding, as it shows that results of an analysis with perceived political attitudes can produce highly different or even opposite results with regard to the mechanisms of intergenerational transmission.

Table 3. Predicting actual and perceived political correspondence of voting intentions within the family

\begin{tabular}{|c|c|c|c|c|c|c|}
\hline & \multicolumn{3}{|c|}{ Actual correspondence } & \multicolumn{3}{|c|}{ Perceived correspondence } \\
\hline & $b$ & $S E$ & $\operatorname{Exp}(B)$ & $b$ & $S E$ & $\operatorname{Exp}(B)$ \\
\hline \multicolumn{7}{|l|}{ Measures among mother/father } \\
\hline Father: Ptv for selected party & $.144 *$ & .068 & 1.155 & $.037 \mathrm{~ns}$ & .025 & 1.037 \\
\hline Mother: Ptv for selected party & $.104 \dagger$ & .054 & 1.110 & $-.028 \mathrm{~ns}$ & .026 & .972 \\
\hline Ideological parental homogeneity & $.149 * *$ & .043 & 1.160 & $.064 \mathrm{~ns}$ & .038 & .728 \\
\hline \multicolumn{7}{|l|}{ Measures among adolescents } \\
\hline General education & $.161 \mathrm{~ns}$ & .142 & 1.175 & $-.041 \mathrm{~ns}$ & .117 & .728 \\
\hline Female & $-.187 \mathrm{~ns}$ & .123 & .830 & $.035 \mathrm{~ns}$ & .102 & .730 \\
\hline Political knowledge & $.110 \dagger$ & .062 & 1.116 & $-.119 *$ & .055 & .888 \\
\hline Talk about politics with parents & $.224 * *$ & .076 & 1.251 & $.110 \mathrm{~ns}$ & .066 & 1.117 \\
\hline Mean Nagelkerke $R^{2}$ (Pooled) & \multicolumn{3}{|c|}{.089} & \multicolumn{3}{|c|}{.014} \\
\hline Mean $\chi^{2}(7 \mathrm{df})($ Pooled $)$ & \multicolumn{3}{|c|}{124.065} & \multicolumn{3}{|c|}{21.204} \\
\hline$n$ & \multicolumn{3}{|c|}{1,991} & \multicolumn{3}{|c|}{1,991} \\
\hline
\end{tabular}

Note: PCSS 2012. Entries are unstandardized b-coefficients from a logistic regression analysis with standard errors $(S E)$ and odds ratios $\operatorname{Exp}(B) . \dagger \mathrm{p}<.10 * p<.05 . * * p<.01 . * * * p<.001$

Particularly for the study of intergenerational transmission of voting intentions, a correct assessment of correspondence across generations is of crucial importance. The main challenge 
for this kind of research is to investigate under what conditions adolescents develop the same political preferences as their parents (Nieuwbeerta and Wittebrood 1995; Zuckerman, Dasović, and Fitzgerald 2007). In the subsequent analysis we ascertain what happens if the actual or the perceived correspondence are used in such an analysis. Since we want to predict adolescent voting intentions and not party correspondence as the dependent variable, we need an analysis for every party separately. By splitting the parties up, we can use the voting intention of both their parents as an independent variable in the model. Note that the comparison between actual and perceived measures is still the main purpose of the analysis and we will therefore not be comparing the parties themselves. For reasons of data reliability, we restrict the analysis to the three largest parties with each over 250 adolescent voters in the sample (i.e., ChristianDemocrats, Greens and Flemish-Nationalists). ${ }^{3}$

In the first model (Table 4), we explain a vote for the Christian-Democrats. Differences between the analysis with real voting preferences and perceived voting preferences are remarkable. In both cases there is a positive and significant relation, but the effects are much weaker in the analysis with real voting intentions than in the analysis with perceived voting intentions. While the 'direct information' analysis allows for 12.9 percent explained variance (mean pooled Nagelkerke pseudo- $R^{2}$ ), this is a massive 39.9 percent in the analysis with perceived voting intention. To express it differently: adolescents who have a preference for Christian-Democrats very often assume that their parents will vote for the same party, while in reality this is not always the case.

Subsequently, we conduct the same analysis for the Greens (Model II in Table 4), and here we can observe 14.8 percent explained variance in the analysis with direct information and

${ }^{3}$ Of the $29.2 \%$ adolescents who intended to vote for the Christian-Democrats, $39.5 \%$ of the mothers voted Christian-Democrats and $32.0 \%$ of the fathers did. Of the $15.3 \%$ adolescents who intended to vote for the Green party, $36.2 \%$ of the mothers voted for the Greens and $19.6 \%$ of the fathers did. Of the $26.4 \%$ of the adolescents who intended to vote for the Flemish Nationalist party, 58.4\% the mothers voted for the Flemish Nationalists, and $60.1 \%$ of the fathers did. 
25.8 percent in the analysis with perceived information. While both for the model using the actual measures as for the model using the predicted measures the coefficients are strong and significant, the model with the direct information is in general weaker than the model with perceived information using the indices for model fit.

Finally, in Model III we run the same for the Nationalist party. If we would rely on perceived correspondence for the transmission of voting for this party, our conclusion would again be that we can explain a very large 42.3 percent of the observed variance. The actual correspondence limits the explained variance to 15.6 percent. All measures for parental voting are highly significant, but they are considerably weaker when we use information obtained directly from the parents. These three models therefore are very clear: relying on perceived correspondence leads to a huge overestimation of the importance of the intergenerational transmission of voting intentions from parents to children. 
Table 4. Predicting adolescent voting intentions using actual and perceived measures of parental voting intentions

\begin{tabular}{|c|c|c|c|c|c|c|}
\hline & \multicolumn{6}{|c|}{ Model I - Adolescent Christian-Democrat vote } \\
\hline & \multicolumn{3}{|c|}{ Actual parental measures } & \multicolumn{3}{|c|}{ Perceived parental measures } \\
\hline & $b$ & $S E$ & $\operatorname{Exp}(B)$ & $b$ & $S E$ & $\operatorname{Exp}(B)$ \\
\hline Mother votes Chr. Democrats & $1.129 * * *$ & .147 & 3.093 & $1.576 * * *$ & .172 & 4.836 \\
\hline Father votes Chr. Democrats & $.671 * * *$ & .147 & 1.956 & $1.558 * * *$ & .160 & 4.751 \\
\hline Girl & $.599 * * *$ & .114 & 1.821 & $.546 * * *$ & .134 & 1.727 \\
\hline General education & $-.022 \mathrm{~ns}$ & .117 & .978 & $-.073 \mathrm{~ns}$ & .136 & .929 \\
\hline Talk politics with parents & $-.033 \mathrm{~ns}$ & .074 & .967 & $-.023 \mathrm{~ns}$ & .087 & .977 \\
\hline Mean Nagelkerke $R^{2}$ (Pooled) & & .129 & & & .399 & \\
\hline Mean $\chi^{2}(5 \mathrm{df})($ Pooled $)$ & & 186.992 & & & 645.331 & \\
\hline \multirow[t]{4}{*}{$n$} & & 1,991 & & & 1,991 & \\
\hline & \multicolumn{6}{|c|}{ Model II - Adolescent Green party vote } \\
\hline & \multicolumn{3}{|c|}{ Actual parental measures } & \multicolumn{3}{|c|}{ Perceived parental measures } \\
\hline & $b$ & $S E$ & $\operatorname{Exp}(B)$ & $b$ & $S E$ & $\operatorname{Exp}(B)$ \\
\hline Mother votes Green & $1.728 * * *$ & .199 & 5.627 & $1.956 * * *$ & .338 & 7.071 \\
\hline Father votes Green & $.838 * *$ & .249 & 2.311 & $1.514 * * *$ & .347 & 4.543 \\
\hline Girl & $.536 * * *$ & .143 & 1.710 & $.541 * * *$ & .154 & 1.718 \\
\hline General education & $.071 \mathrm{~ns}$ & .153 & 1.073 & $.131 \mathrm{~ns}$ & .169 & 1.140 \\
\hline Talk politics with parents & $-.148 n s$ & .100 & .863 & $-.145 \mathrm{~ns}$ & .109 & .865 \\
\hline Mean Nagelkerke $R^{2}$ (Pooled) & & .148 & & & .258 & \\
\hline Mean $\chi^{2}(5 \mathrm{df})($ Pooled $)$ & & 176.246 & & & 317.418 & \\
\hline \multirow[t]{4}{*}{$n$} & & 1,991 & & & 1,991 & \\
\hline & \multicolumn{6}{|c|}{ Model III - Adolescent Fl. Nationalist vote } \\
\hline & \multicolumn{3}{|c|}{ Actual parental measures } & \multicolumn{3}{|c|}{ Perceived parental measures } \\
\hline & $b$ & $S E$ & $\operatorname{Exp}(B)$ & $b$ & $S E$ & $\operatorname{Exp}(B)$ \\
\hline Mother votes Fl. Nationalists & $1.086 * * *$ & .130 & 2.963 & $1.577 * * *$ & .181 & 4.841 \\
\hline Father votes Fl. Nationalists & $.570 * * *$ & .137 & 1.769 & $1.802 * * *$ & .175 & 6.061 \\
\hline Girl & $-.501 * * *$ & .116 & .606 & $-.337 *$ & .138 & .714 \\
\hline General education & $.437 * * *$ & .120 & 1.548 & $.116 \mathrm{~ns}$ & .144 & 1.123 \\
\hline Talk politics with parents & $.190 *$ & .076 & 1.210 & $.187 *$ & .090 & 1.205 \\
\hline Mean Nagelkerke $R^{2}$ (Pooled) & \multicolumn{3}{|c|}{.156} & \multicolumn{3}{|c|}{.423} \\
\hline Mean $\chi^{2}(5 \mathrm{df})($ Pooled $)$ & \multicolumn{3}{|c|}{222.483} & \multicolumn{3}{|c|}{673.465} \\
\hline$n$ & \multicolumn{3}{|c|}{1,991} & \multicolumn{3}{|c|}{1,991} \\
\hline
\end{tabular}

Note: PCSS 2012. Entries are unstandardized b-coefficients from a logistic regression analysis with standard errors (SE) and odds ratios $\operatorname{Exp}(B) . * p<.05 . * * p<.01 . * * * p<.001$ 


\section{Discussion}

In this article, we explored the limitations of social network studies by examining the specific study of transmission of voting intentions within the family. We tested the difference between a study that would rely on information from one key informant in the family (the adolescent child), to studies that would rely on information from all members separately.

Our results show that adolescents often do not know the voting intention of their parents and strongly overestimate the political resemblance between themselves and their parents. Next, we found that there are some important differences between research results using perceived voting intentions versus analyses using actual similarity. On the one hand, political discussion within the family, political knowledge, parental homogeneity and strength of parental preferences each proved to be strongly associated with an actual correspondence of voting intentions, but not with a correspondence of perceived voting intentions. This already suggests that both measures could lead researchers to opposite conclusions if they are not clearly distinguished. Finally, a test using both forms of correspondence showed that perceived correspondence is much more powerful in explaining children's voting intentions, than the actual correspondence measure is. Again, the analysis confirms the important distinction between the two methodological approaches.

The results in this study suggest that researchers using survey data or interviews among individual social network members need to be cautious when interpreting the data obtained from one informant. These findings are not only relevant for political socialization researchers, but could have consequences for other research using a similar design as well, such as social network research investigating the effects of ideological preferences among colleagues, peers, spouses etc. (Mutz 2002a; Huckfeldt, Morehouse Mendez, and Osborn 2004). Previous studies in this respect have shown that the difference between actual and perceived measures within 
social network research can indeed change our interpretation of the interactions between discussion partners (Morehouse Mendez and Osborn 2010).

Studies on political discussion have shown that politics is mostly discussed with conversation partners with similar political views and that people generally try to avoid contested conversations (e.g. Witschge, 2004).The findings in this article, however, suggest that due to a self-directed bias, people might actually overestimate agreement with potential discussion partners. Therefore, they might actually interact more with people they disagree with than they - and researchers - would expect.

Another side note is that we should take into account the findings that these judgment errors also found to be dependent on individual characteristics. For instance gender (Morehouse Mendez and Osborn 2010), discussant expertise (Huckfeldt 2001), but also political knowledge (cfr. supra) are individual determinants that change the accuracy of perceptions of social network members. This means that these findings can have implications for research fields that rely strongly on individual perceptions, such as studies on political discussion, but also for instance for analyses on the relation between political engagement and social network homogeneity (Mutz 2002b; Fitzgerald and Curtis 2012; Huckfeldt, Morehouse Mendez, and Osborn 2004). For these particular studies we should take into account the possibility that an accurate perception of the level of diversity within a social network is dependent on the level of political knowledge of the respondent and the intensity of the interactions with the social network members. If the same logic would apply in other social network settings, we could expect that people with lower levels of political knowledge tend to overestimate the agreement between themselves and their discussion partners (friends, colleagues) more strongly than those with higher levels of political knowledge. Following this, differences in reported network diversity between higher and lower politicized citizens in previous studies could for instance be overestimated (Mutz 2006). 
Finally, a potential limitation to the current study is that we have obtained all the information on perceptions from an adolescent sample. Studies have shown that political knowledge levels tend to increase further into adulthood (Howe 2010; Chan and Clayton 2006), and therefore we could expect the levels of perceptual accuracy in this respect to be higher among adults. This does limit the possibility to generalize the current findings toward an adult sample. Furthermore, one should be careful with comparisons with results from an easier two-party system such as the United States. The limited number of parties obviously increases the likelihood of a correct perception, as 'guessing' will be more effective in such a setting with fewer outcomes. Earlier research within the US context has indeed shown that citizens are quite capable of attributing political positions to certain political groups, such as Democrats and Republicans (Brady and Sniderman 1985). The Belgian party system is an outlier on the other end of the spectrum, as it is one of the most fragmented multiparty settings in Europe (Deschouwer 2009). Within such a multiparty system, we might indeed expect the level of perceptual accuracy to be lower compared to two-party systems (Westholm 1999). Finally, it should be noted that discussions and other interactions with family members could differ from interactions in other social networks that have been studied such as colleagues and neighbors. We could for instance expect that perceptions from members in these more formal or more distant networks will be generally based on more selective information than perceptions from family members. 


\section{References}

Acock, Alan C., and Vern L. Bengtson. 1980. 'Socialization and Attribution Processes: Actual Versus Perceived Similarity Among Parents and Youth.' Journal of Marriage and the Family 42 (3): 501-515.

Brady, Henry E., and Paul M. Sniderman. 1985. 'Attitude Attribution: A Group Basis for Political Reasoning.' The American Political Science Review 79 (4): 1061-1078.

Chan, T. Wing, and Matthew Clayton. 2006. 'Should the Voting Age Be Lowered to Sixteen? Normative and Empirical Considerations.' Political Studies 54 (3): 533-558.

Deschouwer, Kris. 2009. The Politics of Belgium: Governing a Divided Society. Basingstoke: Palgrave Macmillan.

Durrant, Gabriele B. 2009. 'Imputation Methods for Handling Item-nonresponse in Practice: Methodological Issues and Recent Debates.' International Journal of Social Research Methodology 12 (4): 293-304.

Fitzgerald, Jennifer, and K. Amber Curtis. 2012. 'Partisan Discord in the Family and Political Engagement: A Comparative Behavioral Analysis.' Journal of Politics 74 (1): 129-141. Hooghe, Marc, and Joris Boonen. Forthcoming. 'The Intergenerational Transmission of Voting Intentions in a Multiparty Setting: An Analysis of Voting Intentions and Political Discussion Among 15-Year-Old Adolescents and Their Parents in Belgium.' Youth \& Society.

Hooghe, Marc, Ellen Quintelier, Soetkin Verhaegen, Joris Boonen, and Cecil Meeusen. 2012. 'Parent-Child Socialization Study (PCSS) 2012. Technical Report.' Leuven.

Howe, Paul. 2010. Citizens Adrift. The Democratic Disengagement of Young Canadians. Vancouver: The University of British Columbia.

Huckfeldt, Robert. 2001. 'The Social Communication of Political Expertise.' American Journal of Political Science 45 (2): 425-438.

Huckfeldt, Robert, Jeanette Morehouse Mendez, and Tracy Osborn. 2004. 'Disagreement, Ambivalence, and Engagement: The Political Consequences of Heterogeneous Networks.' Political Psychology 25 (1): 65-95.

Jennings, M. Kent, and Richard G. Niemi. 1971. 'The Division of Political Labor Between Mothers and Fathers.' American Political Science Review 65 (1): 69-82. 
1974. The Political Character of Adolescence: The Influence of Families and Schools. Princeton: Princeton University Press.

1981. Generations and Politics: A Panel Study of Young Adults and Their Parents. Princeton: Princeton University Press.

Jennings, M. Kent, Laura Stoker, and Jake Bowers. 2009. 'Politics Across Generations: Family Transmission Reexamined.' The Journal of Politics 71 (3): 782 -799.

Kroh, Martin, and Peter Selb. 2009. 'Inheritance and the Dynamics of Party Identification.' Political Behavior 31 (4): 559-574.

Levine, Jeffrey. 2005. 'Choosing Alone? The Social Network Basis of Modern Political Choice.' In The Social Logic of Politics. Personal Networks as Contexts for Political Behavior, edited by Alan S. Zuckerman, 132-151.

Morehouse Mendez, J., and T. Osborn. 2010. 'Gender and the Perception of Knowledge in Political Discussion.' Political Research Quarterly 63 (2): 269-279.

Mutz, Diana C. 2002a. 'The Consequences of Cross-cutting Networks for Political Participation.' American Journal of Political Science 46 (4): 838-855.

Mutz, Diana C. 2002b. 'Cross-cutting Social Networks: Testing Democratic Theory in Practice.' American Political Science Review 96 (1): 111-126.

Mutz, Diana. C. 2006. Hearing the Other Side: Deliberative versus Participatory Democracy. New York: Cambridge University Press.

Niemi, Richard G. 1974. How Family Members Perceive Each Other : Political and Social Attitudes in Two Generations. New Haven: Yale University Press.

Nieuwbeerta, Paul, and Karin Wittebrood. 1995. 'Intergenerational Transmission of Political Party Preference in The Netherlands.' Social Science Research 24 (3): 243-261.

Tedin, Kent L. 1976. 'On the Reliability of Reported Political Attitudes.' American Journal of Political Science 20 (1): 117-124.

Westholm, Anders. 1999. 'The Perceptual Pathway: Tracing the Mechanisms of Political Value Transfer Across Generations.' Political Psychology 20 (3): 525-551.

Witschge, Tamara. 2004. 'Online Deliberation: Possibilities of the Internet for Deliberative Democracy'. In P. M. Shane (Ed.), Democracy Online: The Prospects for Political Renewal Through the Internet (pp. 109-122). New York and London: Routledge. 
Whitbeck, Les B., and Viktor Gecas. 1988. 'Value Attributions and Value Transmission Between Parents and Children.' Journal of Marriage and the Family 50 (3): 829-840.

Zuckerman, Alan S., Josip Dasović, and Jennifer Fitzgerald. 2007. Partisan Families: The Social Logic of Bounded Partisanship in Germany and Britain. New York: Cambridge University Press. 


\section{Appendix}

\section{Appendix 1. Question wording}

Actual voting intention (child, mother and father survey)

If you could vote in an election for the Belgian parliament today, which party would you vote for?
1. $C D \& V$
4. Open VLD
7. $L D D$

2. Groen

5. Sp.a

8. PvdA

3. $N-V A$

6. Vlaams Belang

9. Other

\section{Perceived voting intention (child survey)}

If your mother could vote in an election for the Belgian parliament today, which party do you think she would vote for?

If your father could vote in an election for the Belgian parliament today, which party do you think he would vote for?

\section{Propensity to vote (parent survey)}

Do you think that you would ever vote for the following parties? $(0=$ definitely not, $10=$ definitely)
1. $C D \& V$
4. Open VLD
7. $L D D$
2. Groen
5. Sp.a
8. $P v d A$
3. $N-V A$
6. Vlaams Belang

\section{Left-right identification (parent survey)}

In political matters, people often talk about 'the Left' and 'the Right'. How would you place your views on a scale from 0 to 10 ? 


\section{Political knowledge (child survey)}

Sum scale of four multiple choice political knowledge questions concerning Belgian politics:

1. Who is Belgians Prime Minister?

2. Who is the Flemish Minister-President?

3. Who are the members of the Flemish government?

4. Who is the President of the European Council?

\section{Political discussion with parents (child survey)}

Sum scale of two highly correlated (.70) questions about political discussion with parents:

1. How often do you talk about politics with your mother?

2. How often do you talk about politics with your father?

1. Never

2. Once or twice

3. Several times

4. A lot

\section{Educational level}

In which educational track are you enrolled?

1. General education

2. Technical education

3. Artistic education

4. Vocational training

This variable is recoded into $1=($ general education $)$ and $0=($ all other forms $)$. 